\title{
Estimating Vertical Foreclosure in U.S. Gasoline Supply
}

\author{
Zava Aydemir*, Stefan Buehler*,**
}

We examine the competitive effects of the vertical integration of gasoline refineries and retailers in the U.S. Adapting the first-order condition approach of static oligopoly games to the analysis of vertically related oligopolies, we develop a novel framework for directly evaluating the strategic foreclosure effect and the efficiency benefits associated with vertical integration. Applying this framework, we find significant evidence for both vertical foreclosure and efficiency benefits. The foreclosure effect dominates the efficiency benefits for more than half of the refining firms in the sample. Vertical foreclosure is found to increase the wholesale price of refined gasoline by 0.2 to 0.6 cents per gallon.

Keywords: vertical integration, separation, foreclosure, market conduct, petroleum industry

JEL: L13, L22, L49, L71.

\footnotetext{
*University of Zurich, Socioeconomic Institute, Hottingerstr. 10, 8032 Zurich, Switzerland; phone: +41-1-634 22 70; fax: +41-1-634 49 87;

**University of St. Gallen, FEW-HSG, Varnbüelstr. 14, 9000 St. Gallen, Switzerland.

e-mail: zaydemir@soi.unizh.ch, sbuehler@soi.unizh.ch.

We are grateful to Manuel Arellano, Ted Frech III, Lars-Hendrik Röller, Armin Schmutzler, Ralph Siebert, Christian Wey, Rainer Winkelmann, Peter Zweifel, Josef Zweimüller, and seminar audiences at the University of Zurich and the University of St. Gallen for helpful discussions. The usual disclaimer applies.
} 


\section{Introduction}

The analysis of the competitive effects of vertical mergers is one of the longstanding issues in antitrust policy. Following the Chicago School's line of argument that a vertically integrated firm cannot benefit from excluding its competitors, ${ }^{1}$ vertical integration was widely accepted to be either competitively neutral or procompetitive from the 1980s on. The U.S. Department of Justice's current "Non-Horizontal Merger Guidelines" (1984) are reminiscent of this rationale when pointing out that, by definition, vertical mergers involve firms from different markets, produce no immediate change in the level of concentration in any of the relevant markets, and are thus less likely than horizontal mergers to create competitive problems. ${ }^{2}$

A surge of recent theoretical developments suggests a reconsideration of the Chicago School's stance towards vertical mergers. Based on the notion of "raising rivals' costs" (Salop and Scheffman 1983, 1987), various authors emphasize that vertical mergers may well have anticompetitive effects. For instance, prominent contributions by Salinger (1988), and Ordover, Saloner and Salop (1990) demonstrate that, in models of vertically related oligopolies, anticompetitive vertical foreclosure of independent downstream rivals may emerge in equilibrium. Based on transaction costs analysis and the concept of incomplete contracts, Hart and Tirole (1990), and Bolton and Whinston (1993) similarly find that independent downstream competitors may be strategically placed at a disadvantage. ${ }^{3}$

However, the policy implications of these studies remains largely unclear. ${ }^{4}$ The main reason for this shortcoming is the fact that the literature tends to

\footnotetext{
${ }^{1}$ Standard references include Bork (1978), and Posner and Easterbrook (1981). Perry (1989) provides a survey. Rubinfeld and Singer (2001) summarize the Chicago School's approach to vertical foreclosure.

${ }^{2}$ The "Non-Horizontal Merger Guidelines" were originally issued as part of "U.S. Department of Justice Merger Guidelines, June 14, 1984". Before the 1980s, U.S. antitrust policy towards vertical mergers meandered between being largely uninterested and relatively hostile. See White (1989) and Kwoka and White (1998) for surveys.

${ }^{3}$ Further contributions include O'Brien and Shaffer (1992), McAfee and Schwartz (1994), Choi and Yi (2000), Church and Gandal (2000), Chen (2001), and Rey and Tirole (forthcoming).

${ }^{4}$ See Klass and Salinger (1995), Reiffen and Vita (1995), and Riordan and Salop (1995) for critical reviews of the foreclosure literature.
} 
focus on demonstrating that foreclosure may be an equilibrium phenomenon if firms are vertically integrated, rather than analyzing the trade off between potential efficiency benefits and anticompetitive effects of vertical integration. In a recent contribution, Riordan (1998) examines this trade off in the context of a dominant firm model, where the dominant firm is more efficient in the production of the final good because of an exogenous cost advantage. He finds that vertical mergers may be welfare improving and provides an observable indicator for welfare improving vertical mergers. ${ }^{5}$

The number of empirical studies on the competitive effects of vertical integration is remarkably small. Even though there is a fair amount of evidence from isolated case studies (Allen 1971; Pass and Hawkins 1972), event studies (Rosengreen and Meehan 1994; Snyder 1995), and econometric studies (McBride 1983; Grimm, Winston and Evans 1992; Waterman and Weiss 1992; Chipty 2001; Gilbert and Hastings 2001; Manuszak 2001), there are no direct empirical tests of strategic foreclosure in real markets. ${ }^{6}$ In particular, the econometric studies mainly focus on estimating possible price or cost differences between integrated and separated firms at the downstream layer and infer, based on the results, strategic behavior on the part of integrated firms at the upstream layer. However, these cost differences may also be explained by factors that are unrelated to the strategic incentives to raise rivals' costs, such as the realization of efficiency gains from vertical integration, or the presence of a positive markup in the upstream market due to imperfect competition. In the latter case, only separated downstream firms face a markup, since vertically integrated retailers secure inputs at the marginal costs of their own upstream suppliers. That is, beside vertical foreclosure, the cost difference between independent and integrated downstream competitors may also be generated by imperfect competition upstream. These two effects, however, are not quantifiable per se without having access to data on the upstream layer of the industry.

\footnotetext{
${ }^{5} \mathrm{~A}$ drawback of his model, however, is that strategic interactions between firms are absent. The welfare analysis is therefore not directly applicable to vertically related oligopolies.

${ }^{6}$ Martin, Normann and Snyder (2001) report direct empirical evidence for vertical foreclosure in experimental markets.
} 
In this paper, we propose a novel framework that enables us to directly test for strategic vertical foreclosure. In contrast to the existing econometric literature on vertical foreclosure, we start from the observation that to provide direct econometric evidence on the vertical foreclosure of firms in the downstream market, one must study strategic behavior on the vertically related upstream market. This observation follows from the fact that, in order to foreclose its downstream rivals, an integrated firm must strategically manipulate its own upstream behavior. This manipulation, in turn, is reflected in the integrated firms' first-order condition for the profit-maximizing choice of its upstream choice variable(s). Therefore, rather than inferring the upstream firms' strategic behavior from estimated cost differences on the downstream market - i.e. from the postulated effects of vertical foreclosure - our framework focuses directly on the causes of vertical foreclosure by estimating and testing for the upstream firms' strategic behavior itself.

We apply our framework to the analysis of the supply of gasoline in the U.S., where the competitive effects of the integration of gasoline refineries and retailers have long been subject to particular scrutiny. A number of states have even enacted so-called "divorcement" regulations that restrict the integration of gasoline refineries and retailers to prevent refineries from attempting to eliminate their franchised dealers through predatory practices (see Blass and Carlton 1999; Vita 1999).

We propose a simple model of vertically related oligopolies that exhibits the essential characteristics of the refining stage of gasoline supply. Within this model, we derive the first-order condition of a profit-maximizing refining firm. It turns out that, apart from an additive foreclosure term, the relevant first-order condition of a vertically integrated refining firm is similar to that of a separated rival. This allows us to isolate the foreclosure effects generated by vertical integration into gasoline retailing. Our framework also allows us to separate potential efficiency gains from the foreclosure effects generated by vertical integration. Letting refineries' marginal costs vary over vertical ownership structures enables us to estimate efficiency benefits from vertical integration. In particular, we control and test for efficiency gains from vertical integration by introducing different marginal cost specifications for 
integrated and separated refining firms. ${ }^{7}$ Using various sources of micro data, we identify and estimate the refining industry's average supply relation. We find significant evidence for both foreclosure effects and efficiency benefits associated with vertical integration. Vertical foreclosure is practiced extensively, in particular by refining firms with large capacities. Strikingly, the foreclosure effect is found to dominate the efficiency benefit for more than half of the refining firms in our sample, which covers all petroleum refining firms active in January 1995. Vertical foreclosure is estimated to increase the wholesale price by 0.2 to 0.6 cents per gallon.

The paper is organized as follows. In section 2, we briefly describe the main economic characteristics of the gasoline refining industry, and discuss its relations to crude oil production and gasoline retailing, respectively. Section 3 sets out a simple theoretical model and derives explicit expressions for the efficiency benefits and the strategic foreclosure effects of vertical integration. Section 4 discusses the empirical specification of the model and the associated problems to be considered when estimating the supply relation. It also provides a short outline of the data sources used for this study. Section 5 reports the estimation results and discusses their economic implications. Section 6 concludes.

\section{The Industry}

The production and supply of gasoline involves a number of vertically related activities, including the exploration and extraction of crude oil (production), the manufacturing of refined gasoline (refining), and the marketing and distribution of gasoline to customers (retailing). ${ }^{8}$ Since we are interested in testing whether vertically integrated refining firms are foreclosing independent gasoline retailers, we henceforth focus our industry description on the

\footnotetext{
${ }^{7}$ Furthermore, we can control for the markup set by the oligopolistic competitors upstream.

${ }^{8}$ As a fourth stage, one could consider the transportation of petroleum products. However, transportation is part of various stages of production and thus difficult to fit into the vertical supply chain. In addition, there is no data available as to which firms are integrated into transportation. See Bindemann (1999) and Martin (2001) for surveys on the vertical structure of the petroleum industry.
} 
refining industry for the reasons outlined above. We discuss the vertical relations to crude oil production and gasoline retailing when necessary. In particular, it will be useful to distinguish refining firms with different degrees of vertical integration.

First, we describe how gasoline is refined and marketed. In 1995, the U.S. petroleum refining industry manufactured three different grades of motor gasoline still in use today: Regular, Midgrade, and Premium. Within each of these grades, gasoline is physically homogeneous. On the wholesale market for refined gasoline, independent retailers purchase gasoline in the different grades either from the rack of terminal facilities, or from dealer tank wagons delivering to retail outlets. The supply on the wholesale market is limited by the refineries' capacities, and the wholesale prices at the terminals tend to equate demand and supply. It is thus reasonable to argue that the CournotNash model is a useful approximation of the competitive process on the wholesale market (Gilbert and Hastings 2001).

The refining industry manufactures the different grades of gasoline through a variety of physical and chemical processes. $^{9}$ In addition to the vertical ownership structure, the refining technology determines the profitability of a firm. As pointed out by Chen $(2002,520)$, the profitability of a refining operation depends on two important elements: (i) a stable supply of crude oil, and (ii) the technical ability to process different qualities of crude oil. The first element suggests that there may be vertical integration economies with crude oil production. The second element indicates that the adoption of upgrading technologies designed to increase the yield of light-end products (such as gasoline) from refining crude oil of a given quality is essential since these products promise higher revenues. Having access to flexible technologies enables a refinery to produce a higher proportion of light fuels from low quality crude oil. However, refineries differ in the extent to which they have adopted these flexible technologies and thus feature different processing costs. According to Masseron (1990), the processing costs depend on a number of refinery characteristics, such as the plant's age, its processing capacity, the complexity of the adopted refining process, and the type of

\footnotetext{
${ }^{9}$ See Leffler (1985) for a non-technical description of the refining process and its distinctive features.
} 
crude oil processed. We will indicate below how we control for the refineries' characteristics in our estimations of the supply relation.

For our analysis, it is crucial to understand the horizontal and vertical structure of the refining industry. The American Petroleum Institute (1996) provides a full sample of the U.S. refineries and their operating capacities as of January 1, 1995. Using the Petroleum Administration for Defense (PAD) districts defined by the Department of Energy, the refining industry's horizontal structure can be summarized as in table 1. There are two things worth noting. First, roughly two thirds of all refineries operate capacities of less than 100'000 barrels per calendar day. Second, the distribution of plant sizes varies considerably across PAD districts. For instance, the large U.S. refineries with capacities above 300'000 barrels per calendar day are almost exclusively located in the Gulf Coast area, whereas the Rocky Mountains district is populated by small plants only. As efficiency gains will be shown to vary with capacity, we should expect considerable regional differences in the competitive effects of vertical integration. We discuss this issue in more detail in section 5 .

$<$ table 1 here $>$

It is well-known that the U.S. oil industry generally exhibits a high degree of vertical integration. In the 1970s Blair $(1976,236)$ already noted:

"[...] the oil industry has developed a pattern of vertical integration $[. .$.$] that is unapproached by any other industry."$

In fact, table 2 shows that a large proportion of the refineries operating in 1995 is either fully or partially vertically integrated, i.e. most refineries are integrated backwards into crude oil production or forwards into gasoline retailing (or both). Yet, there remains a nonnegligable number of independent refineries, which is crucial for directly estimating downstream foreclosure in gasoline retailing.

$<$ table 2 here $>$ 
As pointed out above, our framework is based on a careful analysis of the strategic incentives of vertically integrated refineries. Apart from the advantage of directly measuring foreclosure, this framework dispenses with the need to have micro data on gasoline retailing, as will become clear in the discussion of our theoretical setup. That is, evaluating the competitive effects of the integration of gasoline refiners and retailers exclusively relies almost exclusively on data on the refining stage of the industry. Yet, to derive the supply relation of a refining firm, we need to have a clear view of the working of retail competition. We shall outline this argument in the next section in which we construct our theoretical setup.

\section{Theoretical Setup}

In this section, we set up a simple model of vertically related oligopolies that captures the essential features of the refining industry described in section 2. The theoretical setup presented here comes close to that in Gilbert and Hastings (2001). In contrast to their contribution, we assume that costs of refining crude oil are non-zero.

\subsection{Assumptions}

For simplicity, we focus on the gasoline refining and retailing stages of the industry. ${ }^{10}$ More specifically, we consider an upstream market where refineries sell gasoline on a wholesale market, and a downstream market where retailers distribute gasoline to final customers.

We model the provision of gasoline to final customers as a two-stage game. In the first stage, $n$ refining firms simultaneously choose the gasoline outputs $q_{i}^{w}, i=1, \ldots n$, that they are willing to sell on the wholesale market, taking the wholesale outputs of the other refineries as given. In the second stage, $m$ retailing firms set their retail prices $p_{j}^{r}, j=1, \ldots, m$, taking as given

\footnotetext{
${ }^{10}$ We first explicitly incorporated the crude oil production stage in our theoretical model. This, however, complicates the notation of the cost function to be discussed below, but does not enrich the theoretical setup. For this reason, we omit the oil production stage in our theoretical analysis. However, we will control for the ownership structure in crude oil production in our empirical analysis.
} 
each other's retail price as well as the wholesale price $P^{w}$, where $P^{w}=$ $P^{w}\left(Q^{w}\right), Q^{w}=\sum_{i=1}^{n} q_{i}^{w}$, and $\partial P^{w}\left(Q^{w}\right) / \partial Q^{w}<0$. It should be noted that a vertically integrated refinery $i$ not only sells $q_{i}^{w}$ on the wholesale market, but also produces the amount $q_{i}^{r}$ for its own retail outlet. We assume here that each integrated refining plant has sufficient capacity to fully cover its own retailer's demand. Thus, vertically integrated outlets do not purchase from the wholesale gasoline market as will be outlined formally below.

In our theoretical setup, we maintain the following basic assumptions:

(A1) Refineries produce a homogeneous product and act as Cournot-Nash competitors.

(A2) Retailers produce differentiated products and act as price setters. They face a well-defined demand function $q_{j}^{r}\left(\mathbf{p}^{r}\right)$ for each vector of retail prices $\mathbf{p}^{r}=\left(p_{1}^{r}, \ldots, p_{m}^{r}\right)$.

(A3) One unit of the upstream product is required to produce one unit of the downstream product.

Assumption (A1) is motivated by our above description of the industry. Product differentiation in assumption (A2) rests on the findings of the empirical literature on competition on retail gasoline markets. This literature suggest that retailing firms earn positive markups thanks to product differentiation or tacit collusion (Shepard 1990; Borenstein 1991; Shepard 1991; Borenstein and Shepard 1996; Borenstein et al. 1997; Borenstein and Shepard 2002). The assumption of a well-defined demand function $q_{j}^{r}$ for each retailer implies that there exists a rationing rule which determines retailers' profit functions in case aggregate downstream demand exceeds the upstream capacity constraint. (A3) is a standard assumption of the literature on vertically related markets. We believe it is adequate in the context of the supply of refined gasoline, where one gallon of refined retail gasoline requires one gallon of refined wholesale gasoline.

We solve the model by backwards induction. That is, we first solve for the equilibrium vector of retail prices $\mathbf{p}^{r}=\left(p_{1}^{r}, \ldots, p_{m}^{r}\right)$ at the gasoline stage. Further, since the equilibrium retail price vector depends on the wholesale price, which is taken as given at this stage, we can write it as $\mathbf{p}^{r}=\mathbf{p}^{r}\left(P^{w}\left(Q^{w}\right)\right)$. 
At the first stage of the game, refineries choose their quantities taking into account the optimal price choice $\mathbf{p}^{r}=\mathbf{p}^{r}\left(P^{w}\left(Q^{w}\right)\right)$ of the retailers.

\subsection{Deriving the Supply Relation}

Let us now consider how a refining firm chooses its wholesale output $q_{i}^{w}$. The profit function of refining firm $i$ is given by

$$
\pi_{i}=P^{w}\left(Q^{w}\right) q_{i}^{w}+R_{i}^{r}\left(\mathbf{p}^{r}\left(P^{w}\left(Q^{w}\right)\right)\right)-C_{i}\left(q_{i}^{w}, q_{i}^{r}\left(\mathbf{p}^{r}\left(P^{w}\left(Q^{w}\right)\right)\right)\right),
$$

where $P^{w}\left(Q^{w}\right) q_{i}^{w}$ is the wholesale revenue, $R_{i}^{r}\left(\mathbf{p}^{r}\left(P^{w}\left(Q^{w}\right)\right)\right)$ is the retail revenue, and $C_{i}(\cdot)$ is the cost function, which is nondecreasing in $q_{i}^{w}$ and $q_{i}^{r}$. Note that, by definition, $q_{i}^{r} \equiv R_{i}^{r} \equiv 0$ if refining firm $i$ is vertically separated, i.e. not active in the downstream market.

In Cournot-Nash equilibrium, refining firm $i$ chooses its wholesale output $q_{i}^{w}$ such that

$$
\begin{aligned}
\frac{\partial \pi_{i}}{\partial q_{i}^{w}}=P^{w} & \left(Q^{w}\right)+\frac{\partial P^{w}\left(Q^{w}\right)}{\partial q_{i}^{w}} q_{i}^{w}+\sum_{j} \frac{\partial R_{i}^{r}}{\partial p_{j}^{r}} \frac{\partial p_{j}^{r}}{\partial P^{w}} \frac{\partial P^{w}}{\partial Q^{w}} \\
& -\frac{\partial C_{i}\left(q_{i}^{w}, q_{i}^{r}(\cdot)\right)}{\partial q_{i}^{w}}-\frac{\partial C_{i}\left(q_{i}^{w}, q_{i}^{r}(\cdot)\right)}{\partial q_{i}^{r}}\left(\sum_{j} \frac{\partial q_{i}^{r}}{\partial p_{j}^{r}} \frac{\partial p_{j}^{r}}{\partial P^{w}} \frac{\partial P^{w}}{\partial Q^{w}}\right)=0 .
\end{aligned}
$$

Rearranging (2) yields an adapted version of the well-known first-order condition of a Cournot oligopolist

$$
P^{w}\left(Q^{w}\right)\left[1+\frac{s_{i}^{w}}{\varepsilon^{w}}\right]=\frac{\partial C_{i}\left(q_{i}^{w}, q_{i}^{r}(\cdot)\right)}{\partial q_{i}^{w}}+F_{i}\left(q_{i}^{w}, q_{i}^{r}\right)
$$

where $s_{i}^{w}=q_{i}^{w} / Q^{w}$ is refinery $i$ 's market share in the wholesale market, $\varepsilon^{w}$ is the price elasticity of demand in the wholesale market, and $F_{i}\left(q_{i}^{w}, q_{i}^{r}\right)$ is the foreclosure term defined as

$$
F_{i}\left(q_{i}^{w}, q_{i}^{r}\right) \equiv \underbrace{\frac{\partial C_{i}\left(q_{i}^{w}, q_{i}^{r}(\cdot)\right)}{\partial q_{i}^{r}}\left(\sum_{j} \frac{\partial q_{i}^{r}}{\partial p_{j}^{r}} \frac{\partial p_{j}^{r}}{\partial P^{w}} \frac{\partial P^{w}}{\partial Q^{w}}\right)}_{\text {cost effect }}-\underbrace{\sum_{j} \frac{\partial R_{i}^{r}}{\partial p_{j}^{r}} \frac{\partial p_{j}^{r}}{\partial P^{w}} \frac{\partial P^{w}}{\partial Q^{w}}}_{\text {revenue effect }}
$$


where $\partial q_{i}^{r} / \partial p_{i}^{r}<0, \partial q_{i}^{r} / \partial p_{j}^{r}>0$ for all $j \neq i, \partial R_{i}^{r} / \partial p_{j}^{r}>0$ for all $j \neq$ $i, \partial R_{i}^{r} / \partial p_{i}^{r}<0$, and $\partial p_{j}^{r} / \partial P^{w}>0$ for all $j$. The first three derivatives reflect standard assumptions on demand functions with substitutes, the fourth derivative follows from firm $i$ 's first-order condition for its retail price $p_{i}^{r}$, and the last is a standard equilibrium result for competition with strategic complements.

To understand (3), it is helpful to highlight the differences to the standard first-order condition of a Cournot oligopolist. First, it should be noted that if the refining firm under consideration is vertically separated, $F_{i}\left(q_{i}^{w}, 0\right)=0$. This follows immediately from $q_{i}^{r}=R_{i}^{r} \equiv 0$. That is, a vertically separated refining firm is expected to set the standard Cournot output. Now, consider a vertically integrated firm. The revenue effect in (4) indicates that a vertically integrated refinery may have an incentive to strategically reduce its wholesale output $q_{i}^{w}$ so as to increase its downstream revenue $R_{i}^{r}$. The intuition of this effect is straightforward: A reduction of the wholesale output $q_{i}^{w}$ increases the wholesale price $P^{w}$, which raises independent downstream rivals' costs, forcing them to increase their retail prices. If refinery $i$ 's retail price $p_{i}^{r}$ does not increase too much in response to the change of the wholesale price $P^{w}$, downstream revenue $R_{i}^{r}$ will go up. The additional cost effect incorporated in $F_{i}\left(q_{i}^{w}, q_{i}^{r}\right)$ arises since the integrated refinery optimally adjusts the quantity $q_{i}^{r}$ in response to changes in retail prices. More specifically, a reduction of the wholesale output $q_{i}^{w}$ leads to an increase in the wholesale price $P^{w}$ which induces the separated retailers to raise their retail prizes $p_{j}^{r}$. Thanks to higher prices posted by its competitors, the vertically integrated retailer enjoys an increased own demand $q_{i}^{r}$ which is met by increasing production upstream.

The profitability of a strategic reduction of $q_{i}^{w}$ is ambiguous in general, since the sign of $F_{i}\left(q_{i}^{w}, q_{i}^{r}\right)$ depends simultaneously on the sign of the revenue effect and the cost effect. Nevertheless, first-order condition (3) provides us with a convenient way of testing whether vertical foreclosure is profitable in equilibrium for an integrated refining firm $i . F_{i}\left(q_{i}^{w}, q_{i}^{r}\right)>0$ implies that it pays to strategically reduce the wholesale output $q_{i}^{w}$ relative to the standard Cournot output, since the additional downstream revenues are larger than the associated cost distortions. For $F_{i}\left(q_{i}^{w}, q_{i}^{r}\right)<0$ the argument runs vice versa. Therefore, first-order condition (3) indicates that a strategic reduction 
of $q_{i}^{w}$-i.e. raising rivals' costs - is profitable in equilibrium if and only if $F_{i}\left(q_{i}^{w}, q_{i}^{r}\right)>0$. This provides us with a simple way of testing whether vertical foreclosure is profitable for any given integrated firm $i$ : All we need to do is check the sign of $F_{i}\left(q_{i}^{w}, q_{i}^{r}\right)$. For the empirical analysis of U.S. gasoline supply, we establish the hypothesis that vertical foreclosure arises in equilibrium, i.e. $F_{i}\left(q_{i}^{w}, q_{i}^{r}\right)>0$, and test for it.

As discussed at the outset, vertical integration not only brings about the danger of foreclosure, but also the potential for realizing efficiencies. In fact, vertically integrating firms invariably claim that their merger increases efficiency. First-order condition (3) accounts for this possibility in two ways. First, each refining firm $i$ is associated with an individual marginal cost function $\partial C_{i}(\cdot) / \partial q_{i}^{w}$, i.e. there is room for generic cost differences between firms, whether they are integrated or not. Second, since the retail output of a vertically separated refinery is zero by definition $\left(q_{i}^{r} \equiv 0\right)$, the marginal cost function of refining firm $i$ is evaluated at different arguments under vertical integration and separation. That is, the model presented in this section allows for synergies between refining and retailing that are unrelated to the potential savings of fixed costs.

\section{Empirical Analysis}

In this section, we specify an empirical model of the gasoline refining industry that allows us to evaluate the competitive effects of the vertical integration of gasoline refineries and retailers. Broadly speaking, we follow the "New Empirical Industrial Organization" (NEIO) literature which suggests that, in oligopolistic markets, conduct and unknown cost parameters may be inferred from the responsiveness of prices to changes in demand elasticities and various known cost parameters. ${ }^{11}$ In practice, this amounts to identifying and estimating a set of simultaneous equations - typically a demand function and a supply relation - that are assumed to characterize the equilibrium of the oligopolistic market under consideration. Yet, in contrast to many NEIO

\footnotetext{
${ }^{11}$ See Bresnahan (1989) for a survey. Genesove and Mullin (1998) provide evidence for the validity of the NEIO methodology in the static oligopoly case. Corts (1999) provides a critical review for dynamic models.
} 
studies, we do not attempt to estimate the (horizontal) "average collusiveness of conduct" or the "intensity of competition", but the refining firms' (vertical) strategic behavior with respect to independent retailers under the hypothesis that foreclosure is present in that industry. Recall that, according to assumption (A1), refining firms act as Cournot-Nash competitors. By making this assumption, we thus exogenously determine the intensity of competition on the wholesale market. ${ }^{12}$

\subsection{Specification of the Supply Relation}

The point of departure for constructing the refining industry's empirical supply relation is the theoretical first-order condition given in (3). Rearranging yields

$$
P^{w}=-\frac{s_{i}^{w}}{\varepsilon^{w}} P^{w}+\frac{\partial C_{i}\left(q_{i}^{w}, q_{i}^{r}\right)}{\partial q_{i}^{w}}+F_{i}\left(q_{i}^{w}, q_{i}^{r}\right) .
$$

We go through five steps of specification to fully parameterize this equation.

First, to quantify the foreclosure effect, it is natural to introduce a dummy variable $d_{i}$, which is one for integrated refining firms and zero for others. However, the drawback of estimating the foreclosure effect with a single dummy variable is that possible size-induced differences in the refining firms' incentives to foreclosure independent retailers are ignored. To account for such differences, we interact the dummy variable $d_{i}$ with three additional firm size dummies, $s_{i}^{(t)}, t=2,3,4$, that indicate to which quartile in the distribution of market shares firm $i$ belongs. ${ }^{13}$ For instance, $s_{i}^{(2)}$ equals one if the market share of firm $i$ is in the second quartile, and is zero otherwise, etc. This specification allows the foreclosure effect to vary nonlinearly over firm sizes. We call the respective interaction terms foreclose_s for firms with small market shares (in the second quartile), foreclose_ $m$ for firms with medium-sized market shares (third quartile), and foreclose_ $l$ for firms with large market

\footnotetext{
${ }^{12}$ Note that, in principle, it is straightforward to incorporate the average collusiveness of conduct on the upstream market into our general framework. However, the identification of the supply relation's relevant parameters then becomes more complicated.

${ }^{13}$ Defining the market share as the ratio $s_{i}=q_{i} / Q$ of its refining capacity to the aggregate refining capacity, we calculated this ratio for each firm and constructed the quartiles based on the nation-wide distribution of market shares.
} 
shares (fourth quartile).

Second, to quantify the efficiency effect, we use the interaction term efficiency $\equiv d_{i} \times q_{i, k}$, where $q_{i, k}$ denotes the refining capacity of plant $k$ belonging to firm $i$. The interaction term is intended to control for cost differences between otherwise identical vertically separated and integrated refining plants. Note that this specification allows integration economies to emerge at the plant rather than the firm level (see Masseron 1990, pp. 284). Measuring the efficiency effect at the plant level is crucial for empirically separating the efficiency from the foreclosure effect, which is measured at the firm level. Employing this specification, the correlation of the respective interaction terms turns out to be fairly low $(0.07,0.25$, and 0.47 , respectively).

Clearly, estimating the first-order condition of a refining firm using plant level data is not quite satisfying from a theoretical point of view for firms owning multiple plants. To control for this shortcoming, we introduce the dummy variable nplant, which is one for a firm owning multiple plants and zero otherwise.

Third, in specifying marginal costs, we add five different groups of variables to construct the vector $\mathbf{x}_{i, k}$ of additional explanatory variables: (i) cost variables, such as wages and other factor prices; (ii) refinery characteristics, such as plant age and the type of crude oil processed measured in gravity; (iii) firm characteristics, e.g. whether a firm is a major U.S. company or a major international company etc.; (iv) variables describing a firm's vertical relation to crude oil production, e.g. whether it owns foreign wells, or is backwards integrated, and (v) other control variables, e.g. whether the information on a firm's ownership structure was gathered on the internet.

Fourth, since gasoline is homogeneous within the three grades, as stated above, there is a generic lack of variance for the dependent variable $P^{w}$. To deal with this problem, we use the wholesale gasoline prices of three independent regional submarkets. In each of these independent submarkets, the refining firms are assumed to act as Cournot-Nash competitors. The submarkets - we henceforth call them "regions" - are defined as the following combinations of PAD districts:

- region 1: PAD districts 1 and 3; 
- region 2: PAD districts 2;

- region 3: PAD districts 4 and 5 .

The construction of these regions follows primarily from the pattern of petroleum trade across PAD districts. The data on the movement of petroleum products provided by the Energy Information Administration (1996b, tables 12 and 32) indicate that there is considerable trade between PAD districts 1 and 3, whereas the trade between PAD district 2 and other districts is very limited. It is thus natural to classify PAD districts 1 and 3 , as well as district 2, as regions of their own. The picture is less clear for PAD districts 4 and 5. They could also be treated as regions of their own on the basis of the petroleum movement data. We nevertheless aggregate them to form region 3 , since (with the exception of New Mexico) these two districts are identical to the Census-region "West", which is an important retail market defined by the U.S. Census Bureau. In regions 1 and 3, we use the mean of the respective PAD district prices reported by the Energy Information Administration (1996a).

The theoretical setup outlined in section 3 suggests that in each of these independent submarkets, first-order condition (5) must be satisfied for any active refining firm. Further, it is natural to assume that, besides choosing output, a firm may also choose the location of its plant(s). That is, even though we do not explicitly analyze the choice of a plant's location, we account for the fact that each of the refining firms may choose any of the submarkets considered as a plant's location. That is, the wholesale price is allowed to vary over the different plants. We therefore write the wholesale price as $P_{k}^{w}$.

Fifth, since the wholesale market share $s_{i}^{w}$ is not observable, we treat it as a parameter to estimate and therefore denote it by $\sigma_{i}$. Now consider the wholesale price elasticity $\varepsilon^{w}$. It is well-known that, in general, the upstream price elasticity $\varepsilon^{w}$ may be expressed in terms of the (aggregate) downstream price elasticity $\varepsilon^{r}$ times the elasticity $e$ of the (aggregate) downstream price with respect to changes of the upstream price (Rey and Stiglitz 1995; Slade 1998). That is, for a given downstream price elasticity $\varepsilon^{r}$ and a set of prices $P^{w}$ and $P^{r}$, the simplest parameterization of the wholesale price elasticity is 
given by

$$
\varepsilon^{w}=f\left(\varepsilon^{r}, P^{w}, P^{r} ; \theta\right)=\varepsilon^{r} \times e \equiv \varepsilon^{r} \theta \frac{P^{w}}{P^{r}},
$$

with $\theta \equiv \partial P^{r} / \partial P^{w}$. Employing this linear specification of $e$ and adding an error term $\xi_{k}$ with $E\left[\xi_{k}\right]=0$ yields the empirical supply relation

$$
\begin{aligned}
P_{k}^{w}= & \alpha_{1}-\frac{\sigma_{k}}{\theta_{k} \varepsilon^{r}} P^{r}+\sum_{h \in\{s, m, l\}} \alpha_{h} \times \text { foreclose }_{-} h_{i} \\
& +\alpha_{2} \times \text { efficiency }_{k}+\boldsymbol{\beta}^{\prime} \mathbf{x}_{i, k}+\gamma \times \text { nplant }_{k}+\xi_{k},
\end{aligned}
$$

where the greek letters are the parameters to be estimated. Clearly, the parameters $\sigma_{i}, \theta_{k}$ and $\varepsilon^{r}$ are not identified. This is inconsequential, however, for estimating the parameters of the foreclosure and the efficiency effect, which are of immediate interest.

Under the hypothesis that vertical foreclosure is an equilibrium strategy for vertically integrated firms, we expect $\alpha_{h}, h=s, m, l$, to be positive, which is equivalent to $F_{i}\left(q_{i}^{r}, q_{i}^{w}\right)>0$ in the theoretical setup. Further, under the hypothesis that there are efficiency gains which are increasing in plant size, we expect the sign of the coefficient $\alpha_{2}$ to be negative. Finally, we expect the coefficient $-\frac{\sigma_{k}}{\theta_{k} \varepsilon^{r}}$ to be positive.

\subsection{Identification and Estimation}

When estimating supply relation (7), one has to bear in mind that a number of the explanatory variables are endogenous. For instance, we treat the retail price as endogenous. The prices of crude oil and natural gas liquids, which are important inputs for the refining process, are treated as further endogenous variables. Although, for simplicity, the uppermost layer in the vertical supply chain is not included in our theoretical setup, we acknowledge that the prices for these products are simultaneously determined. ${ }^{14}$ Similarly, quantities are treated as endogenous because of the familiar simultaneity bias, even though the demand side is not explicitly incorporated here. Since the interaction terms are functions of quantities, they are viewed as endogenous. Finally, we

\footnotetext{
${ }^{14}$ Recall that more than two thirds of the refining firms in our sample are integrated backwards into production (see table 2)
} 
treat any variable that deals with location or plant number as endogenous in our empirical specification. In particular, we assume that nplant is correlated with the error term.

Our key identification assumption concerns the choice of instrumental variables. Any variables that are correlated with the endogenous explanatory variables, but uncorrelated with the error term $\xi_{k}$, are appropriate instruments. We use two different sets of instrumental variables, denoted by $A$ and $B$, respectively.

Instrument set $A$ contains the exogenous explanatory variables (including the constant) plus further exogenous variables from the supply side of the market, in particular firm characteristics and variables describing the crude oil production segment of the industry, such as the share of crude oil imports in a PAD district. In total, there are 23 instruments in set $A$.

Instrument set $B$, in turn, includes all variables of instrument set $A$, plus the squares and interaction terms of the continuous exogenous explanatory variables. The total number of instruments in set $B$ is $88 .{ }^{15}$

The number of instruments in both sets easily outnumbers the maximum number of parameters to be estimated. We therefore employ overidentification tests to avoid specification errors.

To construct a benchmark for our estimation results, we first estimate the supply relation using OLS, ignoring the endogeneity problem, but using the White heteroscedasticity consistent covariance matrix estimator (White 1980). We then use the GMM estimator proposed by Hansen (1982) to estimate the model parameters. This estimator exploits population moment conditions and provides both consistent parameter estimates and standard errors that are robust to heteroscedasticity.

\subsection{Data}

In this section, we briefly describe our data sources as well as their use in the present study. A detailed description of our variables and the summary statistics, is given in the appendix (tables A2 and A3, respectively).

\footnotetext{
${ }^{15}$ See table A1 in the appendix for a detailed list of the variables in instrument sets $A$ and $B$.
} 
The main data source for our analysis is the report "Entry and Exit in U.S. Petroleum Refining 1948-1995" compiled by the American Petroleum Institute (1996). It provides detailed data on the ownership and capacity histories of petroleum refineries operating in the U.S. from January 1948 through January 1995. In particular, it identifies the location and the ownership of all 159 refineries operating positive capacities in 1995 at the parent company level.

Using the "U.S.A. Oil Industry Directory 1995" edited by Pennwell (1995), we determined the vertical structure of the refining firms listed in the American Petroleum Institute's (1996) report. For the small number of refining firms that are not listed in the Pennwell (1995) directory, we used information gathered from the internet to determine the vertical structure. For three firms in the data set, we were unable to determine the vertical structure, and we therefore excluded them from our sample. For eight of the 156 remaining refineries, the age of the refining plant is not reported in the American Petroleum Institute's (1996) report. We thus ended up with 148 observations for our estimations.

The Oil Industry Directory further provides useful information on firm characteristics, e.g. whether the firm is a major U.S. company, a major international company, owned by a foreign company, etc. We used this information to construct our instrument sets.

Two reports prepared by the Energy Information Agency (1996a,b), the "Petroleum Marketing Annual 1995", and the "Petroleum Supply Annual 1995", provide detailed information on the aggregate wholesale and retail prices of gasoline per state and PAD district, as well as the pattern of crossdistrict trade and the type of crude oil processed in the various refining districts. We used them to construct our three regional wholesale and retail markets, the associated price and quantity variables, and a number of refinery characteristics variables.

Finally, we used data provided by the Bureau of Labor Statistics (2000) for the relevant wages of refinery operators, and general and operations managers. This data was supplemented by the natural gas price for the industrial sector provided by the Energy Information Administration's (2001) report "Natural Gas 2000". 


\section{$5 \quad$ Results and Interpretation}

This section presents our estimates of the U.S. refining industry's average supply relation in 1995. First, we report the estimation results for equation (7). Second, we discuss the robustness of these results, employing various alternative specifications of the average supply relation. Third, we use our parameter estimates to derive statements about the relative importance of the foreclosure and efficiency effect associated with vertical integration into gasoline retailing. Finally, we analyze the impact of the foreclosure effect on the level of wholesale prices.

\subsection{Estimated Supply Relation}

Table 3 reports the estimates for equation (7). Column (I) lists the OLS estimates which account for heteroscedasticity but ignore the endogeneity problem. They serve as a benchmark for the GMM estimates reported in columns (II) and (III), using instrument sets $A$ and $B$, respectively. The table is divided into four groups of coefficient estimates: The first group contains the variables of immediate interest, including the retail price, the three foreclosure interaction terms and the efficiency interaction term. The second group contains various variables describing the refineries' input markets, such as factor prices and imports of crude oil. The third group controls for the specific characteristics of a plant or a refining firm. The last group contains miscellaneous variables. In the following, we shall primarily discuss the coefficient estimates of the first group.

$$
<\text { table } 3 \text { here }>
$$

To begin with, consider the OLS estimates. Even though the coefficient estimates are biased and inconsistent, they are in line with our above hypothesis that vertical integration generates both foreclosure and efficiency effects. For instance, the coefficients of the variables foreclose_ $m$ and foreclose_ $l$ are both positive and significant, whereas the coefficient of foreclose_s is negative and insignificant. These estimates suggest that a refining firm's incentive to foreclose independent downstream rivals does increase with its size. Further, the coefficient of efficiency is negative and significant. That is, we find 
preliminary evidence for both vertical foreclosure and integration economies. The input variables are found to have the expected impact on marginal costs. All factor prices enter positively into the equation, and backwards integration into crude oil production appears to reduce marginal costs. High crude oil imports also tend to reduce the wholesale price of refined gasoline. Finally, the coefficients of the various plant and firm characteristics are consistent with basic economic intuition.

Now consider the GMM estimates reported in column (II), which are based on instrument set $A$. The coefficient estimates deviate considerably from the OLS estimates in column (I). More specifically, the signs of various coefficients change, and the standard errors generally increase dramatically. In fact, the only variable found to be significant is the retail price, and the adjusted $R^{2}$ drops to 0.80 . It should be pointed out, however, that such effects are commonly observed when changing from OLS to an instrumental variable (IV) estimator. Davidson and MacKinnon (1993, 224), for instance, note that IV estimators may be extremely inefficient, and the finite-sample distributions may be very different from the asymptotic ones, especially when the instruments have little ability to explain the endogenous regressors. To deal with the latter problem, we used the more comprehensive instrument set $B$ to estimate the supply relation.

The GMM estimates reported in Column (III) are based on instrument set $B$. The $\chi^{2}$ statistic indicates that the null hypothesis of no overidentification cannot be rejected. Note that the standard errors are considerably reduced relative to column (II), and with the exception of foreclose_s, all variables of immediate interest are significant. The coefficient estimates of the foreclosure terms again indicate that the incentives to foreclose independent retailers increase with size. More specifically, large integrated refining firms (in terms of market shares) have a stronger incentive to foreclose independent retailers than small integrated refining firms. Similarly, the efficiency effect is found to increase with refinery size. Furthermore, all input prices have the expected positive signs and are significant. The negative coefficient of back indicates that there are significant economies of backwards integration into crude oil production. Also, a high crude oil import share tends to reduce the wholesale price, which is clearly in line with basic economic intuition. There is only 
one important difference to the OLS results: When estimating with GMM, the coefficients of the foreclosure and the efficiency variables tend to become larger in absolute value, i.e., once we account for the endogeneity problem, the competitive effects of vertical integration become more pronounced. This finding may be explained by the familiar simultaneity-bias of OLS.

\subsection{Robustness and Alternative Specifications}

We estimated a number of alternative model specifications to check the robustness of the results reported in table 3. More specifically, we used alternative parameterizations of the unobservable wholesale market share $s_{i}^{w}$, experimented with a different set of regional submarkets, and employed other specifications of marginal costs. We discuss each of these changes in specification in turn.

One way of dealing with the non-observability of wholesale market shares entails using the mean of wholesale market shares $\bar{s}^{w}=\frac{1}{n} \sum_{i} s_{i}^{w}=\frac{1}{n}$ to estimate an adapted version of (7) where $n$ denotes the (observable) number of refining firms active in a submarket. Instead of the retail price, one can then use the wholesale price divided by the number of refining firms active in this submarket as a regressor, with the wholesale price elasticity $\varepsilon^{w}$ being identified immediately. A serious disadvantage of this specification, however, is the elimination of the retail price from the estimation equation. That is, readily available information on the working of oligopolistic competition in the vertically related refining industry is discarded. ${ }^{16}$ It is thus unsurprising that equation (7) turns out to provide a better fit to the data. More disturbingly, the wholesale price elasticity is estimated to be positive rather than negative with this particular specification. Nevertheless, the qualitative results for the foreclosure and the efficiency effects are similar for both specifications.

A casual way of dealing with the non-observability of wholesale market shares involves simply using a refinery's relative capacity $s_{i}=q_{i} / Q$ instead of $s_{i}^{w}$. One can then use the wholesale price multiplied by $s_{i}$ to estimate the

\footnotetext{
${ }^{16}$ In fact, the refining industry is treated as a standard horizontal industry in terms of pricing.
} 
average supply relation, i.e., the retail price is again eliminated from the estimation equation. The estimates then turn out to be similar to those just mentioned. It should be noted, however, that in addition to the problems discussed above, using $s_{i}$ instead of $s_{i}^{w}$ introduces a measurement error problem that makes it impossible to find instruments for the wholesale price, since the error term is a function of the wholesale price by construction.

In addition, we estimated equation (7) using a different set of regional submarkets, where the PAD districts 4 and 5 were treated as two distinct regions (rather than one aggregated region). This change in the definition of independent regional submarkets did not affect the qualitative results of our analysis. We also introduced alternative specifications of marginal costs. In particular, we employed the additional variables $q_{i, k}$ and $q_{i, k}^{2}$, which turned out to be insignificant. We are aware that this specification might have introduced a multicollinearity problem, since the correlation of $q_{i, k}$ and efficiency is very high (the correlation coefficient is 0.92). Unsurprisingly, the efficiency benefit of integration was estimated to be insignificant with this particular specification. Finally, we rescaled the efficiency interaction term to avoid potential numerical problems when estimating equation (7). Yet, the numerical estimates were largely unaffected by this transformation.

In the next section, we shall therefore use the GMM estimates reported in column (III) of table 3 for our analysis of the role that strategic vertical foreclosure plays in the U.S. refining industry.

\subsection{Quantifying the Foreclosure Effect}

We have pointed out above that both the incentives to foreclose independent retailers and the efficiency benefits of integration increase with size. As a result, it is generally ambiguous whether the foreclosure effect dominates the efficiency effect associated with vertical integration. Using our GMM estimates of the average supply relation reported in column (III) of table 3 , we now calculate the regional share of integrated refining firms for which the strategic incentive to foreclose independent retailers is larger than the efficiency benefit of vertical integration.

First, for each quartile $t=2, \ldots, 4$, we calculate the critical firm size 
$q^{*}(t)$, below which the foreclosure effect dominates the efficiency benefit. ${ }^{17}$ Second, we determine the number of integrated firms $\tilde{n}^{(t)}$ that are smaller than this critical value and compare it to the total number of firms $n^{(t)}$ in the respective quartile. Note that the calculation of $\tilde{n}^{(t)} / n^{(t)}$ is entirely a ceteris paribus exercise, i.e., alternative factors determining the pricing rule are held constant when carrying out these calculations. Table 4 reports the results of this exercise.

$<$ table 4 here $>$

Strikingly, table 4 indicates that the foreclosure effect dominates the efficiency effect for more than half of the refining firms in the sample. The share of refining firms for which the foreclosure effect associated with integration dominates the efficiency effect varies considerably over the regional submarkets: While the foreclosure effect dominates for merely $21 \%$ of the refining firms in the East and Golf Coast region, it dominates for almost 90\% of the firms in the Rocky Mountains and West Coast region. Similarly, the foreclosure effect dominates for none of the small firms with market shares in the second quartile, but for almost all of the large firms with market shares $\mathrm{n}$ the fourth quartile. That is, a refining firm with a large regional market share - rather than a firm with large absolute capacity — has strong incentives to foreclose independent downstream rivals.

To quantify the impact of the foreclosure effect on the wholesale price, it is instructive to compare the observed wholesale price $P^{w}$ with the wholesale price $\tilde{P}^{w}$ predicted by the model in the absence of foreclosure (see table 5). ${ }^{18}$

$$
<\text { table } 5 \text { here }>
$$

Table 5 indicates that in the Midwest (region 2) as well as the Rocky Mountains and the West Coast (region 3), where vertical foreclosure is practiced extensively, the wholesale price is increased by roughly 0.5 cents per

\footnotetext{
${ }^{17} \mathrm{As}$ an example, consider the critical firm size $q^{*}(t)$ for a refining firm with a market share $s_{i}$ in the fourth quartile $(t=4)$. The critical firm size is calculated by solving the equation $0.814-1.07 \times 10^{-6} q^{*}(4)=0$. The solution is given by $q^{*}(4)=760,750$ barrels per calender day.

${ }^{18}$ To calculate $\tilde{P}^{w}$, we evaluated the model at the means of the explaining variables, setting the foreclosure terms equal to zero.
} 
gallon. In the East and Gulf Coast region (region 1), in turn, where half of the medium-sized and none of the large firms appear to practice foreclosure, the predicted price effect of vertical foreclosure is somewhat lower $(0.2$ cents per gallon). That is, even though a majority of the refining firms in the sample are practicing vertical foreclosure, the overall price effect of foreclosure is relatively small. One should keep in mind, however, that even such relatively modest price increases may be able to generate considerable rents for integrated refining firms.

\section{Conclusions}

In this paper, we have proposed a novel framework for evaluating the competitive effects of the vertical integration of gasoline refineries and retailers. Our framework is based on the insight that to examine strategic foreclosure on the retail market, one must study the vertically integrated firms' strategic behavior on the wholesale market. Applying this simple rationale, we analyze the supply of gasoline in the U.S. More specifically, we estimate the petroleum refining industry's supply relation in 1995 and derive statements about the competitive effects of vertical integration from the coefficient estimates.

The parameter estimates turn out to be in line with the predictions of the theoretical literature and basic economic intuition. We find significant evidence that both foreclosure and efficiency effects are associated with vertical integration. Strikingly, our estimates also suggest that the foreclosure effect dominates the efficiency effect for more than half of the refining firms in the U.S. The overall price effect of vertical foreclosure is estimated to be 0.2 to 0.6 cents per gallon.

There are two natural extensions to our analysis. First, note that the dominating foreclosure effect for more than half of the integrated firms may suggest that vertical integration generates adverse welfare effects. Yet, such a conclusion would be hasty, since the net effect of the refining firms' strategic behavior on the set of retail prices is generally undetermined. It would thus be interesting to estimate the effect that strategic manipulations of the wholesale price have on the prices set by individual retailers. One could then derive statements about the welfare effects of vertical mergers. Second, 
one could follow another branch of the NEIO literature and treat the intensity of competition on the wholesale market as a variable to be estimated, rather than imposing a particular level of intensity by assuming Cournot competition. By doing this, one could check whether the set of assumptions suggested by the special characteristics of the refining industry is supported by econometric evidence.

\section{Appendix}


Table A1: List of Instruments

\begin{tabular}{|c|c|}
\hline Instrument set $A$ & Instrument set $B$ \\
\hline Exogenous Explaining Variables & Exogenous Explaining Variables \\
\hline w_rop & w_rop \\
\hline w_gm & w_gm \\
\hline crud_imp & crud_imp \\
\hline ref_age & ref_age \\
\hline gravity & gravity \\
\hline foreign & foreign \\
\hline coop & coop \\
\hline conglom & conglom \\
\hline maj_int & maj_usa \\
\hline maj usa & maj int \\
\hline internet & internet \\
\hline constant & constant \\
\hline Further Exogneous Variables & Further Exogneous Variables \\
\hline w_purch & w_purch \\
\hline $\mathrm{w}$ indeng & $\mathrm{w}$ indeng \\
\hline w_mandr & w_mandr \\
\hline p_coal & p_coal \\
\hline crud_stk & crud_stk \\
\hline statenum & statenum \\
\hline padd & padd \\
\hline other & other \\
\hline frgnwell & frgnwell \\
\hline sulfur & sulfur \\
\hline ca & ca \\
\hline & $\begin{array}{l}\text { Squares and Interaction Terms of } \\
\text { Continous Exogenous Variables }\end{array}$ \\
\hline & w_rop \\
\hline & w_gm \\
\hline & w_purch \\
\hline & $\mathrm{w}$ _indeng \\
\hline & w_mandr \\
\hline & p_elect \\
\hline & year_own \\
\hline & age \\
\hline & sulfur \\
\hline & gravity \\
\hline \multicolumn{2}{|c|}{ Total \# of Instruments } \\
\hline 23 & 88 \\
\hline
\end{tabular}




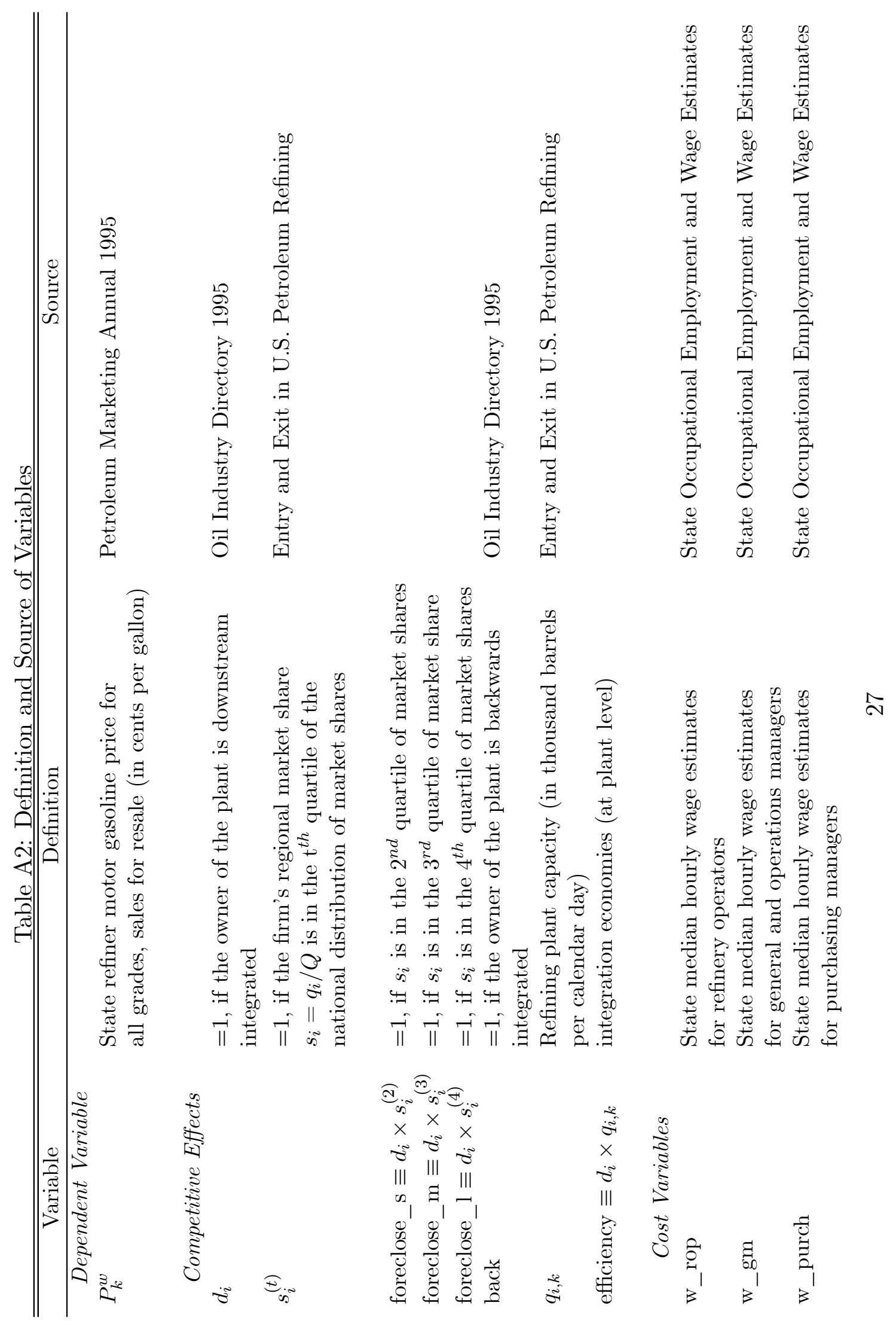




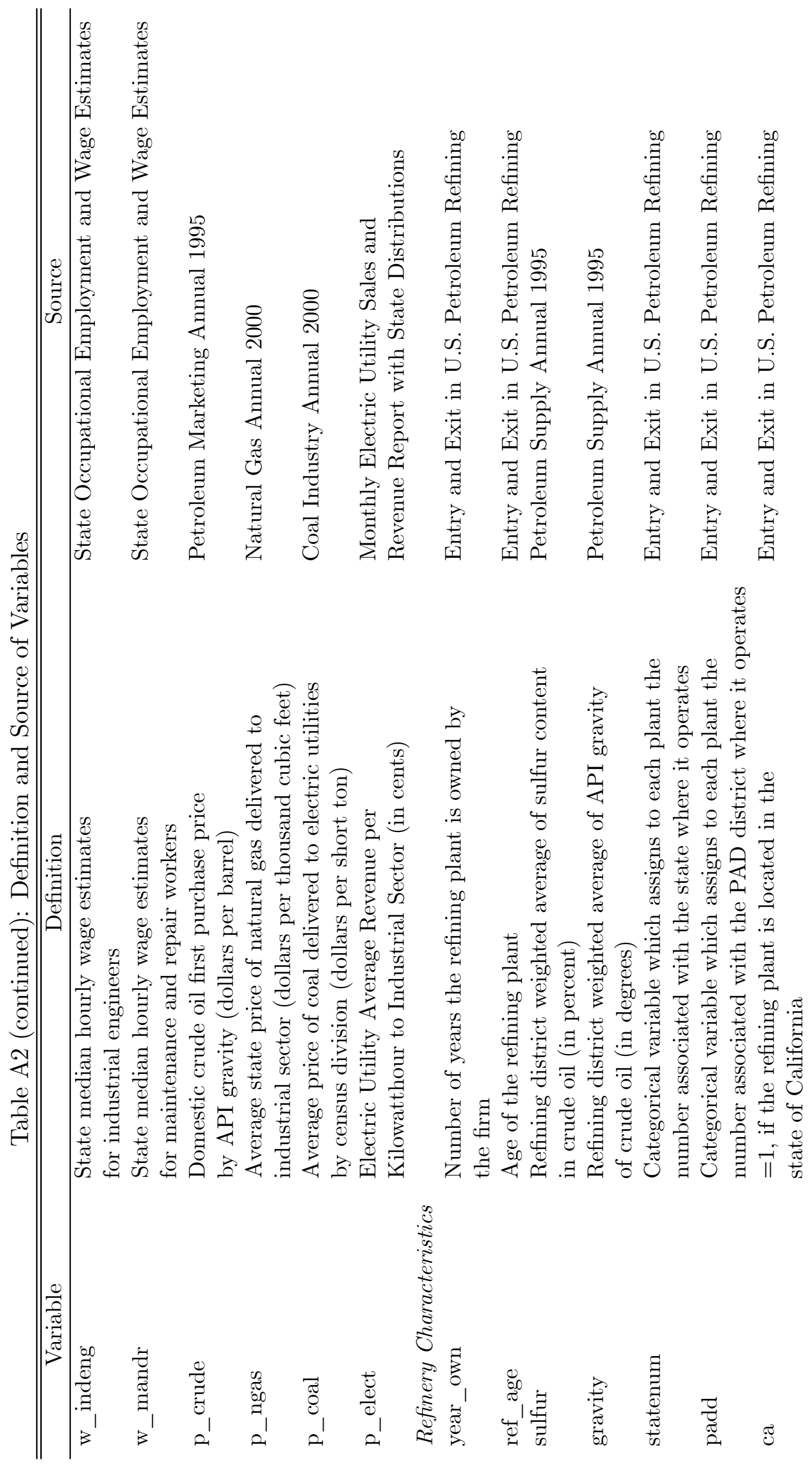




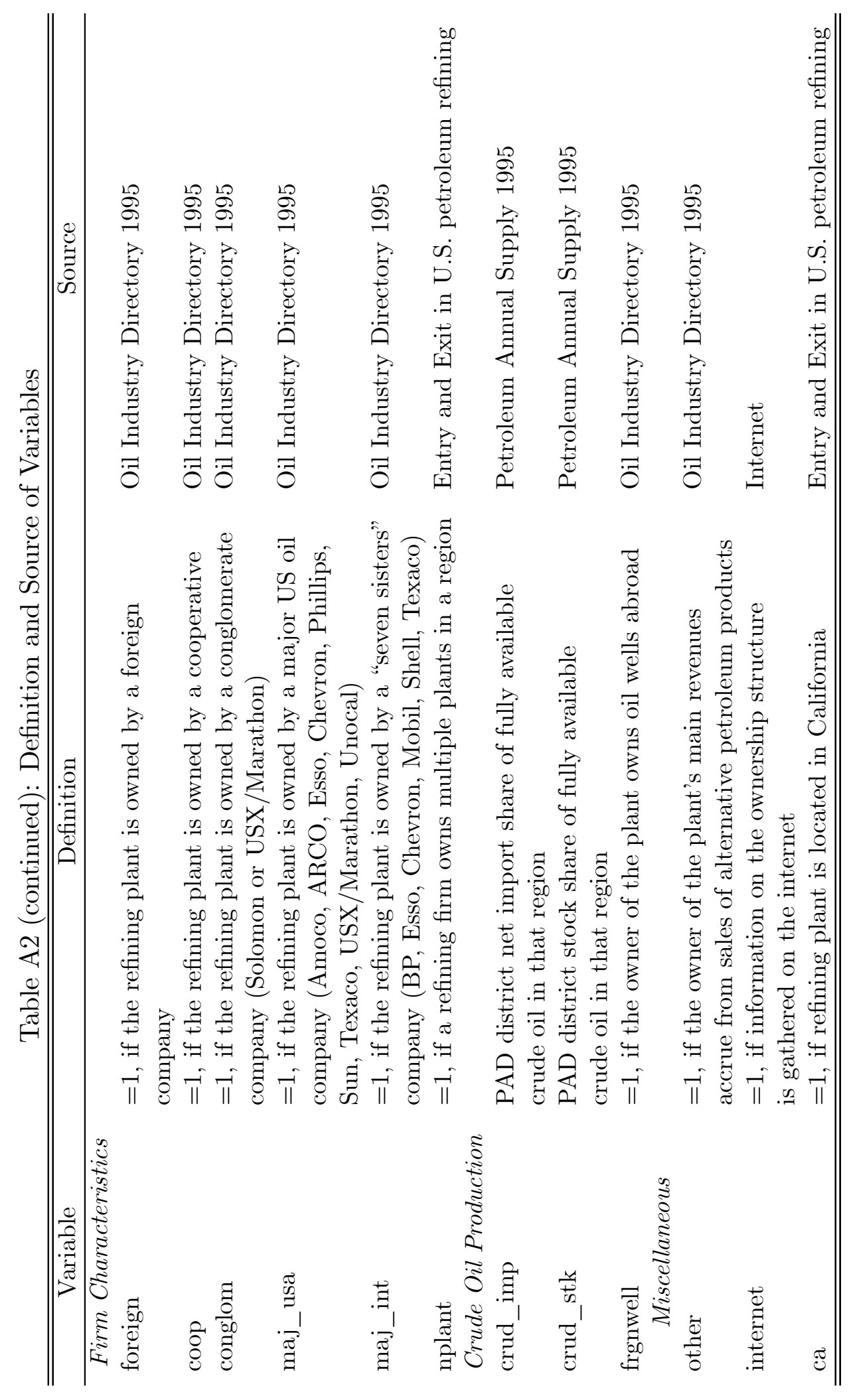


Table A3: Descriptive Statistics

\begin{tabular}{|c|c|c|c|c|}
\hline$\overline{\text { Variable }}$ & Mean & Std. Dev. & Min & Max \\
\hline Dependent Variable & & & & \\
\hline $\begin{array}{l}P_{k}^{w} \\
\quad \text { Competitive Effects }\end{array}$ & 62.708 & 3.155 & 59.900 & 67.150 \\
\hline$d_{i}$ & 0.75 & 0.434 & 0 & 1 \\
\hline foreclose_s $\equiv d_{i} \times s_{i}^{(2)}$ & 0.176 & 0.382 & 0 & 1 \\
\hline foreclose_m $\equiv d_{i} \times s_{i}^{(3)}$ & 0.209 & 0.408 & 0 & 1 \\
\hline foreclose $\_1 \equiv d_{i} \times s_{i}^{(4)}$ & 0.270 & 0.446 & 0 & 1 \\
\hline back - & 0.615 & 0.488 & 0 & 1 \\
\hline$q_{i, k}$ & 98599.190 & 93566.35 & 1000 & 433000 \\
\hline $\begin{array}{c}\text { efficiency } \equiv d_{i} \times q_{i, k} \\
\text { Cost Variables }\end{array}$ & 85839.29 & 97467.22 & 0 & 433000 \\
\hline w_rop & 19.271 & 2.574 & 11.924 & 26.669 \\
\hline $\mathrm{w} \_\mathrm{gm}$ & 25.202 & 5.515 & 16.606 & 43.278 \\
\hline w_purch & 21.414 & 3.558 & 14.454 & 30.206 \\
\hline $\mathrm{w}$ _indeng & 25.392 & 2.293 & 19.142 & 30.700 \\
\hline w_mandr & 11.648 & 1.658 & 9.194 & 16.263 \\
\hline p_crudoil & 14.980 & 2.144 & 11.140 & 16.240 \\
\hline p_ngas & 4.068 & 0.950 & 1.326 & 8.931 \\
\hline p_coal & 23.011 & 4.768 & 15.063 & 35.582 \\
\hline p_elect & 4.161 & 1.000 & 2.722 & 9.835 \\
\hline Refinery Characteristics & & & & \\
\hline year_own & 25.162 & 16.665 & 1 & 48 \\
\hline ref_age & 41.081 & 12.043 & 3 & 48 \\
\hline sulfur & 1.141 & 0.261 & 0.560 & 1.760 \\
\hline $\begin{array}{l}\text { gravity } \\
\quad \text { Firm Characteristics }\end{array}$ & 31.553 & 4.026 & 25.510 & 39.160 \\
\hline foreign & 0.135 & 0.343 & 0 & 1 \\
\hline coop & 0.027 & 0.163 & 0 & 1 \\
\hline conglom & 0.047 & 0.213 & 0 & 1 \\
\hline maj_usa & 0.291 & 0.456 & 0 & 1 \\
\hline maj_inter & 0.189 & 0.393 & 0 & 1 \\
\hline nplant & 0.507 & 0.502 & 0 & 1 \\
\hline $\begin{array}{l}\text { Crude Oil Production } \\
\text { crud imp }\end{array}$ & 0.469 & 0.291 & 0.088 & 1.000 \\
\hline crud_stk & 0.064 & 0.018 & 0.022 & 0.086 \\
\hline frgnwell & 0.581 & 0.495 & 0 & 1 \\
\hline Miscellaneous & & & & \\
\hline other & 0.149 & 0.357 & 0 & 1 \\
\hline internet & 0.223 & 0.418 & 0 & 1 \\
\hline ca & 0.149 & 0.357 & 0 & 1 \\
\hline
\end{tabular}




\section{References}

Allen, B.T. (1971): "Vertical Integration and Market Foreclosure: The Case of Cement and Concrete", Journal of Law and Economics, 14, 251274 .

Amemiya, T. (1985): Advanced Econometrics. Cambridge, Massachusetts.

American Petroleum Institute (1996): Entry $\&$ Exit in U.S. Petroleum Refining, 1948-1995. Washington, D.C.

Bindemann, K. (1999): "Vertical Integration in the Oil Industry: A Review of the Literature", Journal of Energy Literature, 5, 3-26.

Blair, J. (1976): The Control of Oil. New York.

Blass, A.A., Carlton, D.W. (1999): "The Choice of Organizational Form in Gasoline Retailing and the Costs of Laws Limiting That Choice", NBER Working Paper 7435, Cambridge, Massachusetts.

Bolton, P., Whinston M.D. (1993): "Incomplete Contracts, Vertical Integration, and Supply Assurance", Review of Economic Studies, 60, 121-148.

Borenstein, S. (1991): "Selling Costs and Switching Costs: Explaining Retail Gasoline Margins", RAND Journal of Economics, 22, 354-369.

Borenstein, S., Cameron, C., Gilbert, R. (1997): "Do Gasoline Prices Respond Asymmetrically to Crude Oil Price Changes?", Quarterly Journal of Economics, 112, 306-339.

Borenstein, S., Shepard, A. (2002): "Sticky Prices, Inventories, and Market Power in Wholesale Gasoline Markets", RAND Journal of Economics, 33, 116-139.

Borenstein, S., Shepard, A. (1996): "Dynamic Pricing in Retail Gasoline Markets", RAND Journal of Economics, 27, 229-251.

Bork, R.H. (1978): The Antitrust Paradox. New York.

Bresnahan. (1989): "Empirical Studies of Industries With Market Power", in: Schmalensee, R., Willig, R.D. (Eds.): Handbook of Industrial Organization, Vol. 2. Amsterdam, 1011-1107.

Bureau of Labor Statistics (2000): 2000 State Occupational Employment and Wage Estimates. Washington, D.C.

Chen, M.Y. (2002): "Survival Duration of Plants: Evidence from the US 
Petroleum Refining Industry", International Journal of Industrial Organization, 20, 517-555.

Chen, Y. (2001): "On Vertical Mergers and Their Competitive Effects", RAND Journal of Economics, 32, 667-685.

Chevron (1996): Motor Gasolines Technical Review. San Francisco.

Chipty, T. (2001): "Vertical Integration, Market Foreclosure, and Consumer Welfare in The Cable Television Industry", American Economic Review, 91, 428-453.

Choi, J.P., Yi, S.S. (2000): "Vertical Foreclosure with the Choice of Input Specification", RAND Journal of Economics, 31, 717-743.

Church, J., Gandal, N. (2000): "Systems Competition, Vertical Merger and Foreclosure", Journal of Economics and Management Strategy, 9, 565-579.

Corts, K.S. (1999): "Conduct Parameters and the Measurement of Market Power", Journal of Econometrics, 88, 227-250.

Davidson, R., MacKinnon, J.G. (1993): Estimation and Inference in Econometrics. New York, Oxford.

Energy Information Administration (2001): Natural Gas 2000. Washington, D.C.

Energy Information Administration (1996a): Petroleum Marketing Annual 1995. Washington, D.C.

Energy Information Administration (1996b): Petroleum Supply Annual 1995. Washington, D.C.

Gilbert, R., Hastings, J. (2001): "Vertical Integration in Gasoline Supply: An Empirical Test of Raising Rivals' Costs", University of California at Berkeley (mimeo).

Genesove, D., Mullin, W.P. (1998): "Testing Static Oligopoly Models: Conduct and Cost in the Sugar Industry", RAND Journal of Economics, 29, 355-377.

Grimm, C.M., Winston, C., Evans, C.A. (1992): "Foreclosure of Railroad Markets", Journal of Law and Economics, 35, 295-310.

Hansen, L.P. (1982): "Large Sample Properties of Generalized Method of Moments Estimators", Econometrica, 50, 1029-1054.

Hart, O., Tirole, J. (1990): "Vertical Integration and Market Foreclosure", 
Brooking Papers on Economic Activity, Special Issue, 205-276.

Klass, M.W., Salinger, M.A. (1995): "Do New Theories of Vertical Foreclosure Provide Sound Guidance for Consent Agreements in Vertical Merger Cases?", Antitrust Bulletin, Fall, 667-698.

Kwoka, J.E., White, L.J. (1998): The Antitrust Revolution, 3rd edition. New York.

Leffler, W.L. (1985): Petroleum Refining for the Non-Technical Person. Tulsa. Manuszak, M.D. (2001): "The Impact of Upstream Mergers on Retail Gasoline Markets", Carnegie Mellon University (mimeo).

Martin, S. (2001): "Petroleum", in: Adams, W., Brock, J. (Ed.): The Structure of American Industry, 10th edition, New Jersey, 28-56.

Martin, S., Normann, H.T., Snyder, C.M. (2001): "Vertical Foreclosure in Experimental Marktes", RAND Journal of Economics, 32, 466-496.

Masseron, J. (1990): "Finished Products Supply: Refining", in: Masseron, J. (Ed.): Petroleum Economics, 4th edition, Paris, 233-295.

McAfee, R.P., Schwartz, M. (1994): "Opportunism in Multilateral Vertical Contracting: Nondiscrimination, Exclusivity, and Uniformity", American Economic Review, 84, 210-230.

McBride, M.E. (1983): "Spatial Competition and Vertical Integration: Cement and Concrete Revisited", American Economic Review, 73, 1011-1022.

Newey, W.K. (1984): "A Method of Moments Interpretation of Sequential Estimators", Economics Letters, 14, 201-206.

O'Brien, D.P., Shaffer, G. (1992): "Vertical Control with Bilateral Contracts", RAND Journal of Economics, 23, 299-308.

Ordover, J.A., Saloner, G., Salop, S.C. (1990): "Equilibrium Vertical Foreclosure", American Economic Review, 80, 127-142.

Pass, C.L., Hawkins, K.H. (1972): "Exclusive Dealing, Supplier Ownership of Outlets and the Public Interest: The Petrol Case", Antitrust Bulletin, 17, 567-595.

Pennwell (1995): U.S.A. Oil Industry Directory 1995. Tulsa.

Posner, R.A., Easterbrook, F.H. (1981): Antitrust: Cases, Economic Notes and Other Materials. 2nd edition. St. Paul.

Perry, M.K. (1989): "Vertical Integration: Determinants and Effects", in: 
Schmalensee, R., Willig, R.D. (Eds.): Handbook of Industrial Organization, Vol. 1. Amsterdam, 183-255.

Reiffen, D., Vita, M. (1995): "Is There New Thinking on Vertical Mergers? A Comment", Antitrust Law Journal, 63, 917-941.

Rey, P., Stiglitz, J. (1995): "The Role of Exclusive Territories in Producers' Competition", RAND Journal of Economics, 26, 431-451.

Rey, P., Tirole, J. (forthcoming): "A Primer on Foreclosure", in: Armstrong, M., Porter, R.H. (Eds.): Handbook of Industrial Organization, Vol. 3. Amsterdam.

Riordan, M. (1998): "Anticompetitive Vertical Integration by a Dominant Firm", American Economic Review, 88, 1232-1248.

Riordan, M.H., Salop, S.C. (1995): "Evaluating Vertical Mergers: A PostChicago Approach", Antitrust Law Journal, 63, 513-568.

Rosengren, E.S., Meehan, J.W. (1994): "Empirical Evidence on Vertical Foreclosure", Economic Enquiry, 32, 303-317.

Rubinfeld, D.L., Singer, H.J. (2001): "Vertical Foreclosure in Broadband Access?", Journal of Industrial Economics, 49, 299-318.

Salinger, M.A. (1988): "Vertical Mergers and Market Foreclosure", Quarterly Journal of Economics, 103, 345-356.

Salop, S.C., Scheffman, D.T. (1987): "Cost-Raising Strategies", Journal of Industrial Economics, 36, 19-34.

Salop, S.C., Scheffman, D.T. (1983): "Raising Rivals' Cost", American Economic Review Papers and Proceedings, 73, 267-271.

Shepard, A. (1990): "Pricing Behavior and Vertical Contracts in Retail Markets", American Economic Review Papers and Proceedings, 80, 427431.

Shepard, A. (1991): "Price Discrimination and Retail Configuration", Journal of Political Economy, 99, 30-53.

Slade, M. (1998): "Strategic Motives for Vertical Separation: Evidence from Retail Gasoline Markets ", Journal of Law, Economics, and Organization, 14, 84-113.

Snyder, C.M. (1995): "Empirical Studies of Vertical Foreclosure", Industry Economics Conference Paper and Proceedings, University of Melbourne and Bureau of Industry Economics, 7, 47-70. 
Tirole, J. (1988): The Theory of Industrial Organization. Cambridge, Massachusetts.

Vita, M.G. (1999): "Regulatory Restrictions on Vertical Integration and Control: The Competitive Impact of Gasoline Divorcement Polices", Washington, D.C., mimeo.

Waterman, D., Weiss, A.A. (1996): "The Effects of Vertical Integration Between Cable Television Systems and Pay Cable Networks", Journal of Econometrics, 72, 357-395.

White, H. (1980): "A Heteroskedasticity-Consistent Covariance Matrix and a Direct Test for Heteroskedasticity", Econometrica, 48, 817-838.

White, L.J. (1989): "The Revolution in Antitrust Analysis of Vertical Relationships: How Did We Get from There to Here?", in: Larnere, R.J., Meehan, J.W. (Eds.): Economics and Antitrust Policy. Westpoint, Connecticut. 
Table 1: Horizontal Structure (Number of Refineries)

\begin{tabular}{ccccccc}
\hline \hline & \multicolumn{5}{c}{ PAD district } & \multicolumn{3}{c}{} \\
Capacity* & 1 & 2 & 3 & 4 & 5 & Total \\
\hline $0<100$ & East Coast & Midwest & Gulf Coast & Rocky Mnts & West Coast & \\
$100<200$ & 4 & 21 & 29 & 14 & 23 & 93 \\
$200<300$ & 2 & 3 & 13 & 0 & 9 & 33 \\
$300<400$ & 0 & 0 & 3 & 0 & 3 & 16 \\
$400<500$ & 0 & 1 & 2 & 0 & 0 & 3 \\
\hline Total & 12 & 32 & 55 & 14 & 35 & 3 \\
\hline
\end{tabular}

*in thousand barrels per calendar day

Table 2: Vertical Structure (Number of Refineries)

\begin{tabular}{lcccccc}
\hline \hline \multirow{2}{*}{$\begin{array}{l}\text { Type of } \\
\text { Integration }\end{array}$} & 1 & 2 & 3 & 4 & 5 & Total \\
\hline full & East Coast & Midwest & Gulf Coast & Rocky Mnts & West Coast & \\
upstream & 8 & 18 & 28 & 6 & 19 & 79 \\
downstream & 1 & 2 & 8 & 0 & 1 & 12 \\
no integration & 1 & 10 & 12 & 3 & 6 & 32 \\
\hline \multicolumn{1}{c}{ Total } & 2 & 2 & 7 & 5 & 9 & 25 \\
\hline
\end{tabular}


Table 3: Estimated Supply Relation (Dependent Variable: $P_{k}^{w}$ )

\begin{tabular}{|c|c|c|c|c|c|c|}
\hline & \multicolumn{2}{|c|}{$\begin{array}{c}\text { (I) } \\
\text { OLS }\end{array}$} & \multicolumn{2}{|c|}{$\begin{array}{c}\text { (II) } \\
\text { GMM } \\
\text { Instrument Set } A\end{array}$} & \multicolumn{2}{|c|}{$\begin{array}{c}\text { (III) } \\
\text { GMM } \\
\text { Instrument Set } B\end{array}$} \\
\hline & Estimate & Std. Err. & Estimate & Std.Err. & Estimate & Std.Err. \\
\hline \multicolumn{7}{|c|}{ competitive effects } \\
\hline$P^{r}$ & 0.926 & 0.011 & 0.721 & 0.202 & 0.915 & 0.008 \\
\hline foreclose_s & -0.013 & 0.077 & 1.209 & 1.676 & 0.026 & 0.065 \\
\hline foreclose_m & 0.267 & 0.082 & -1.064 & 2.514 & 0.600 & 0.074 \\
\hline foreclose_l & 0.383 & 0.093 & 3.034 & 2.354 & 0.814 & 0.070 \\
\hline efficiency & $-6.8 \mathrm{E}-7$ & $2.8 \mathrm{E}-7$ & $-5.67 \mathrm{E}-6$ & 0.000 & $-1.07 \mathrm{E}-6$ & 3.03E-7 \\
\hline \multicolumn{7}{|l|}{ input } \\
\hline w_rop & 0.018 & 0.010 & 0.045 & 0.057 & 0.010 & 0.005 \\
\hline w_gm & 0.023 & 0.005 & 0.014 & 0.037 & 0.021 & 0.004 \\
\hline p_crude & 0.043 & 0.024 & -0.229 & 0.412 & 0.029 & 0.020 \\
\hline p_ngas & 0.065 & 0.027 & 0.232 & 0.264 & 0.041 & 0.020 \\
\hline crud_imp & -3.230 & 0.147 & -1.558 & 1.598 & -3.007 & 0.066 \\
\hline back & -0.062 & 0.055 & 0.265 & 1.378 & -0.267 & 0.062 \\
\hline \multicolumn{7}{|l|}{ characteristics } \\
\hline ref_age & -0.002 & 0.002 & 0.004 & 0.013 & -0.003 & 0.002 \\
\hline gravity & 0.032 & 0.013 & 0.029 & 0.149 & 0.026 & 0.009 \\
\hline foreign & -0.025 & 0.064 & 0.911 & 1.663 & -0.040 & 0.061 \\
\hline coop & 0.160 & 0.070 & -1.032 & 1.516 & 0.108 & 0.079 \\
\hline conglom & -0.140 & 0.096 & 0.087 & 1.107 & -0.131 & 0.083 \\
\hline maj_int & -0.155 & 0.068 & -0.524 & 1.021 & -0.164 & 0.052 \\
\hline maj_usa & 0.038 & 0.072 & 1.030 & 1.480 & -0.006 & 0.056 \\
\hline \multicolumn{7}{|l|}{ miscellaneous } \\
\hline nplant & -0.158 & 0.061 & -1.418 & 2.637 & -0.306 & 0.058 \\
\hline internet & 0.020 & 0.090 & 1.003 & 1.265 & 0.012 & 0.056 \\
\hline constant & -27.466 & 1.389 & -5.588 & 19.613 & -25.722 & 0.966 \\
\hline Observations & 148 & & 148 & & 148 & \\
\hline$\chi^{2}$ & & & 0.01 & & 38.3 & \\
\hline$R^{2}$ & 0.99 & & 0.80 & & 0.99 & \\
\hline
\end{tabular}


Table 4: Share of Firms with Dominating Foreclosure Effect

\begin{tabular}{lcccc}
\hline \hline & $2^{\text {nd }}$ quartile & $3^{\text {rd }}$ quartile & $4^{\text {th }}$ quartile & \\
$\tilde{n}^{(2)} / n^{(2)}$ & $\tilde{n}^{(3)} / n^{(3)}$ & $\tilde{n}^{(4)} / n^{(4)}$ & Total \\
\hline Region & $0 / 10$ & $4 / 8$ & $0 / 1$ & $4 / 19$ \\
Midwest & $0 / 4$ & $7 / 7$ & $4 / 4$ & $11 / 15$ \\
Rocky Mnts and West Coast & $0 / 2$ & $5 / 5$ & $10 / 10$ & $15 / 17$ \\
\hline Total & $0 / 16$ & $16 / 20$ & $14 / 15$ & $30 / 51$ \\
\hline
\end{tabular}

Note: $\tilde{n}^{(t)}$ denotes the number of firms in the $t^{t h}$ quartile in the distribution of firm size. $n^{(t)}$ is the total number of firms in the respective quartile.

Table 5: Observed and Predicted Wholesale Prices (Cents per Gallon)

\begin{tabular}{lccc}
\hline \hline Region & $P^{w}$ & $\tilde{P}^{w}$ & $\left(P^{w}-\tilde{P}^{w}\right)$ \\
\hline East and Gulf Coast & 60.8 & 60.6 & 0.2 \\
Midwest & 59.9 & 59.4 & 0.5 \\
Rocky Mnts and West Coast & 67.15 & 66.6 & 0.55 \\
\hline
\end{tabular}

Note: $P^{w}$ denotes the actual wholesale price. $\tilde{P}^{w}$ denotes the predicted value for the wholesale price in the absence of foreclosure effects. 